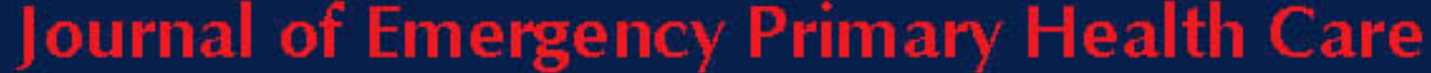

An International elournal of Prehospital Care Research, Education, clinical Practice, Policy and Service Delivery

\title{
EDITORIAL
}

\section{Ambulance Education - Past, Present and Future}

Article No. 990091

\section{Dr. Hugh Grantham}

The evolution of ambulance education over recent years has been dramatic with a move from an essentially skills based approach to a comprehensive tertiary based education system. Against this back drop of evolution, a need to unify the approach to education has been identified.

The first Adelaide symposium in 1995 laid the basis for agreement on standards of ambulance officers and for the establishment of a national body to address education. The second Adelaide education symposium which occurred in July of this year was a major land mark in the development of a uniform approach to education.

Through the actions of a few dedicated visionaries, the seeds of the first symposium eventually germinated and gave rise to the Education Committee of the Convention of Ambulance Authorities. Unlike previous committees and interactions which have focussed largely on interstate comparisons, this committee is promoting the environment in which a uniform National educational system will grow.

Education is currently provided by a number of ambulance based state education units and a number of independent tertiary educational institutions. The challenge is to create an education environment in which all providers choose to participate. The Adelaide education symposium examined the drivers impacting on the direction of education for the future and noted a change in expectations as ambulance was challenged to move from a primarily transport model to a need to provide more and more definitive treatment in the field. This has huge education implications.

Community expectations are becoming more sophisticated and the expectations of the employers in ambulance are driven by a need to balance provision of appropriate care with work force numbers and changing attitudes to work.

Currently, ambulance education lacks an independent external accrediting body as seen in medical and nursing education. The issue of accreditation has always been difficult to address as accreditation has been seen to be synonymous with control and standardisation. A reluctance to embrace accreditation over the years has developed as a consequence of a response to the prospect of control. The 2004 Adelaide symposium identified that accreditation does not necessarily mean standardisation and that variation is of value to the ambulance industry. The symposium also identified the need for education to be responsive to the needs of the industry including type of practice and work force needs. The workforce needs impact in terms of numbers and differing requirements for different situations. 
From the Adelaide symposium, the Ambulance Education Committee has been challenged to develop a system of external accreditation which recognises the value of maintaining variation, while responding to the needs of industry and providing the employer with an accurate assessment of the education strengths of particular courses. When this challenge has been met we will have created an environment that will allow education to lead the professional development of the industry into the future.

The first steps were taken when a need to establish the symposia and the education committee were identified. The committee is now functional and has proposed to the Convention the appointment of a project officer to develop a model which will be able to independently evaluate courses. The project officer is being appointed and the project scoped at this moment. 2006 will see the first independent evaluation of courses and the start of a new era of collaboration between educational providers and employers. Everyone involved in ambulance education has something to contribute and something to learn. Ultimately the beneficiaries of this project will be our patients, while in improving the treatment of our patients we will benefit the individual ambulance professional, the education provider and the ambulance industry. Accreditation, when seen in this light is a liberating enabler and not the oppressive impediment that concerned us all a few years ago. Any remaining fears should dissipate once the evaluation model has been developed and demonstrated in 2005.

Dr Hugh Grantham 